\title{
THE POST GRADUATE PROGRAM IN NURSING OF THE FEDERAL UNIVERSITY OF SANTA CATARINA: 40 YEARS CONTRIBUTING TO THE EXCELLENCE IN EDUCATION
}

The year of 2016 is special for the Programa de Pós-Graduação em Enfermagem (PEn) of the Universidade Federal de Santa Catarina (UFSC). By completing 40 years of a successful career, the PEn/UFSC has the joy of sharing with the public their accomplishments. Here, we include the recognition of excellence at the international level by obtaining the concept 6 in the evaluation made by the Coordination for the Improvement of Higher Education Personnel (Capes) in 2010 and consolidated in 2013.

The PEn/UFSC was created in 1976 with the Master's Program and later on, in the year of 1993 the doctoral program was built. Both of the programs are focused in qualifying nurses and others healthcare professionals with a university degree, who are interested in acting within the field of health. Throughout this time, the program has confirmed its amplitude with expressive integration in a regional, national and international level. In May of the current year, the program, has graduated 680 master's professionals, 292 doctors and 48 post-doctors from Brazil and other countries. Fact that contributes expressively with the academic training of health professionals, but mainly with nurses.

This program has an outstanding performance in promoting certification of masters and doctors through the participation in interinstitutional courses driven initially by the Network for the Promotion of Post-Graduate Programs in the Southern Region since 1990. The program has collaborated with the Universidade Federal do Parana, the Universidade Federal de Santa Maria, the Universidade Federal do Rio Grande do Sul, the Universidade Federal de Pelotas and the Fundação Rio Grande. Subsequently, the PEn/ UFSC expanded its activities to the Universidade Federal do Mato Grosso, the Universidade de Passo Fundo, the Universidade de Caxias do Sul, the Universidade do Contestado, the Universidade do Vale do Itajai and the Universidade Comunitária da Região de Chapecó.

In this mode, the program has graduated 220 masters and 25 doctors and also promoted the creation of their own post graduate programs in these regions. It is encouraging to see that the development of the post-graduate programs in the South, is due greatly to the efforts of the program. It is also important to mention the formation of three groups of Interinstitutional PhD Program (DINTER) held with the Universidade Federal do Pará, the Universidade Federal do Rio Grande do Norte and the Universidade do Estado do Amazonas (currently been developed with 17 students).

The contribution of the PEn/UFSC transcend the Brazilian borders and extends to Latin Ibero-America and other countries. Thus, with regards the international collaboration, since its inception in 1976 to the current date, the program has graduated 14 masters, 13 doctors and seven post-doctors. Therefore, 34 international professionals from ten countries: Peru, Costa Rica, Argentina, Ecuador, Colombia, Chile, Mexico, Uruguay, Portugal and Spain. Additionally, there are nine international post-graduate students in the process of training and certification from countries like Pakistan and Angola. The Program also maintains exchange collaboration with different universities in Germany, France, Spain, United Kingdom, Canada, United States, Mexico and Portugal.

Another important highlight concerns the participation of the PEn/UFSC in the Capes Thesis Award. In ten editions, the program received the award in six of them, with three top awards (2008, 2011 and 2015) and three honorable mentions (2006, 2012 and 2014).

By promoting an ongoing renewal movement, the PEn/UFSC went through six systematic and comprehensive assessments, since its inception, always in search of increasing the quality of the formation process and the qualification of the human process. In its last reformulation, in 2010, as a result of an intensive restructuration of the program, the program created two areas of concentration: Philosophy and HealthCare in Nursing and, Education and Work in Health and Nursing. With that, the program sought to promote an adequate space of consolidation and responsibility with the university and the Brazilian 
Nursing.

In order to meet the needs of performance in teaching, research, management and extension, the program expanded substantially its infrastructure in May, 2013. Thereby, the program opened the Center for Research and Technology of Care in Nursing and Health (CEPETEC) located in the Nursing School Building. This space holds the 13 research laboratories of technology in different areas of knowledge that support the ten research lines of the two areas of concentration of the program.

Currently the faculty is composed by 32 professors, promoting the development of 32 macro-research projects with funding and the production of 360 articles published in high impact journals (Qualis $\mathrm{A} 1, \mathrm{~A} 2$ and B1), in the last three years. It is important to highlight that from the faculty members, 12 professors are CNPq researchers of productivity (two 1A, two 1B, one IC, one ID, six PQ2) and two researchers of Technological Development.

With regards the knowledge transfer process in the area of nursing and health, the program keeps with a lot of dedication the Text \& Context Nursing Journal, classified in the Qualis Capes as A2. The Journal was created in January of 1992, having its first edition published in June of that year. Since then, has been a relevant organ of disclosure intended to publish the technical-scientific production related to the health area and in particular, to Nursing. The Journal is characterized as a scientific journal of national and international circulation, that publishes articles in Portuguese, English and Spanish.

The PEn/UFSC also proudly has accompanied their graduated students that develop activities of teaching and mentoring in the stricto sensu level. The program helps the graduated professor that have funded research projects; those who exercise political and administrative activities or that stand out as leaders in the Brazilian Nursing Association (ABEn) and/ or in the Regional Council of Nursing (COREn). The program even offers assistance to the graduated professional that hold a position as university coordinators, headquarters departments in the graduate or post-graduate level or even in commissions of health and education.

This story of success is the result of a collective work of faculty members, students, and administrative and management personnel, who, since the creation of the PEn/UFSC has been looking for the academic excellence.

Vânia Marli Schubert Backes

Coordinator of the Programa de Pós-Graduação em Enfermagem, Universidade Federal de Santa Catarina

(Term 2013-2016)

Odaléa Maria Brüggemann

Sub-coordinator of the Programa de Pós-Graduação em Enfermagem, Universidade Federal de Santa Catarina

(Term 2013-2016) 